\title{
Superconductivity, Electron Paramagnetic Resonance, and Raman Scattering Studies of Heterofullerides with Cs and Mg
}

\author{
V. A. Kulbachinskii, B. M. Bulychev, V. G. Kytin, A. V. Krechetov, \\ E. A. Konstantinova, and R. A. Lunin \\ Low Temperature Physics Department, Physics Faculty, Moscow State University, 119991 GSP-1, Moscow, Russia \\ Correspondence should be addressed to V. A. Kulbachinskii, kulb@mig.phys.msu.ru
}

Received 9 June 2008; Accepted 23 October 2008

Recommended by Victor Moshchalkov

In the present study, the results of investigation of physical properties of heterofullerides $\mathrm{A}_{3-x} \mathrm{M}_{x} \mathrm{C}_{60}(\mathrm{~A}=\mathrm{K}, \mathrm{Rb}, \mathrm{Cs}, \mathrm{M}=\mathrm{Be}, \mathrm{Mg}$, $\mathrm{Ca}, \mathrm{Al}, \mathrm{Fe}, \mathrm{Tl}, x=1,2)$; as well as $\mathrm{RbCsTlC}_{60}, \mathrm{KCsTlC}_{60}$, and $\mathrm{KMg}_{2} \mathrm{C}_{60}$ are described. All of the fullerides were synthesized by the exchange reactions of alkaline fullerides with anhydrous metal halides. Superconductivity was found in $\mathrm{RbCsTlC}_{60}$ and $\mathrm{KCsTlC}_{60}$.

Copyright ( 2008 V. A. Kulbachinskii et al. This is an open access article distributed under the Creative Commons Attribution License, which permits unrestricted use, distribution, and reproduction in any medium, provided the original work is properly cited.

\section{Introduction}

It is well known that critical temperature of superconducting transition $\left(T_{c}\right)$ of alkali-intercalated fullerides depends on the crystalline lattice parameter [1]. The value of $T_{c}$ increases with the increase in some interval of the lattice parameter a. Thus one can expect that heterofullerides with Cs may possess higher $T_{c}$ values because of larger $a$ values, compared to fullerides with $\mathrm{K}$ and $\mathrm{Rb}$. Fulleride $\mathrm{Cs}_{3} \mathrm{C}_{60}$, synthesized by standard gaseous method, has primitive cubic lattice and is not a superconductor. Under high pressure, $\mathrm{Cs}_{3} \mathrm{C}_{60}$ is a superconductor with $T_{c}=40 \mathrm{~K}$ in FCC lattice as well as $\mathrm{K}_{3} \mathrm{C}_{60}$ and $\mathrm{Rb}_{3} \mathrm{C}_{60}$. The efforts to synthesize fullerides with composition from $\mathrm{Cs}_{2} \mathrm{C}_{60}$ to $\mathrm{Cs}_{6} \mathrm{C}_{60}$ in a solvent (toluol) give amorphous or polymerized non-superconducting substances [2]. It is worth to note that for $\mathrm{KCs}_{2} \mathrm{C}_{60}$ and $\mathrm{RbCs}_{2} \mathrm{C}_{60}$ fullerides, both methods produce superconductors with the same $T_{c}$.

We showed that exchange reaction of homofullerides of $\mathrm{K}$ and $\mathrm{Rb}$ with anhydrous group 8-10 metal halides rear earth metal halides in tetrahydrofuran substitute a part of alkali metal to Ln or Fe with surviving of superconductivity $[3,4]$. The open question is as follows: are these substances superconductors themselves or they are partly defected fullerides $\mathrm{K}_{3} \mathrm{C}_{60}$ and $\mathrm{Rb}_{3} \mathrm{C}_{60}$ ? To check the effectiveness of exchange reaction, we tried to synthesize by the same method the heterofullerides with Cs. The Cs fullerides under normal conditions are non-superconductors, that is why the observation of superconductivity when some atoms of Cs replaced by metal of will be an evidence of superconducting properties of heterofullerides with other not alkali metals.

\section{Experimental}

Toluene and tetrahydrofuran (THF) were cleared and absolutized by standard techniques. Anhydrous metal chlorides were also obtained by standard techniques; chlorides of beryllium, aluminum, and iron were synthesized by chlorination of metal by dry chlorine; chlorides of magnesium, calcium, barium, and strontium were received by thermal drying of hydrated salts with ammonium chloride in vacuum; thallium chloride was commercially available. Potassium, rubidium, and caesium fullerides were synthesized by reaction of fullerite with the stehiometric quantity of metal in the environment of toluene at $120-130^{\circ} \mathrm{C}$ by a method described in [5].

Synthesis of the initial of alkali metal fullerides, partial removal of toluene, blending of fulleride suspension with suspension of heterometal halogenide in THF, drying of products of reaction, and their packaging in ampoules for definition of temperature of superconducting transition were carried out in vacuum in the full glass facilities equipment. 
In more detail, the technique is described in $[4,5]$. The exchange reactions are writing as

$$
\begin{aligned}
& \mathrm{A}_{4} \mathrm{C}_{60}+\mathrm{MCl}_{2} \stackrel{\text { THF }}{\longrightarrow} \mathrm{A}_{2} \mathrm{MC}_{60}+2 \mathrm{ACl}, \\
& \mathrm{A}_{5} \mathrm{C}_{60}+2 \mathrm{MCl}_{2} \stackrel{\mathrm{THF}}{\longrightarrow} \mathrm{AM}_{2} \mathrm{MC}_{60}+4 \mathrm{ACl}, \\
& \mathrm{A}_{5} \mathrm{C}_{60}+\mathrm{M}^{\prime} \mathrm{Cl}_{3} \stackrel{\text { THF }}{\longrightarrow} \mathrm{A}_{2} \mathrm{M}^{\prime} \mathrm{C}_{60}+3 \mathrm{ACl}, \\
& \mathrm{A}_{3} \mathrm{C}_{60}+\mathrm{M}^{\prime \prime} \mathrm{Cl} \stackrel{\mathrm{THF}}{\longrightarrow} \mathrm{A}_{2} \mathrm{M}^{\prime \prime} \mathrm{C}_{60}+\mathrm{ACl},
\end{aligned}
$$

where A-K, Rb, Cs; M-Be, Mg, Ca; $\mathrm{M}^{\prime}$-Al, Fe; $\mathrm{M}^{\prime \prime}$ - Tl.

The measurements of RFA were carried out with Guinier G670 HUBER. The sample of fulleride was located in a thin-walled glass capillary which was brazed in vacuum. $\mathrm{C}^{13}$ NMR spectra are measured by Bruker AC-200 under the one-pulse program with duration of excitation impulse 4 microseconds. Intervals between impulses was 2 seconds. For measurements of Raman spectra Perkin-Elmer Raman spectrometer with He-Ne, the laser with wavelengths of 632.7 nanometers was used. Measurements of EPR spectra were carried out on EPR spectrometer Bruker (model Elexsys 500) in the X-range with flow cryostat in temperature interval of $105-300 \mathrm{~K}$. The values of g-factors were calculated based on reference line of $\mathrm{Mn}^{2+}$ ions in $\mathrm{MgO}(g=1.9812)$.

Temperatures of superconducting transitions of fullerides were defined by standard low-frequency induction method by measuring the temperature dependence of a magnetic susceptibility in temperature interval $4.2<T<$ $300 \mathrm{~K}$.

\section{Results and Discussion}

\subsection{Superconductivity}

Fullerides $\mathrm{RbCsTlC}_{60}$ and $\mathrm{Rb}_{2} \mathrm{TlC}_{60}$ have superconducting transition temperature $T_{c}$ higher than others. For KCsTlC 60 , the value of $T_{c}=21.7 \mathrm{~K}$ is the highest for fullerides with $\mathrm{K}$. Fullerides with composition $\mathrm{Cs}_{3-x} \mathrm{M}_{x} \mathrm{C}_{60}(\mathrm{M}$-metal, $x=$ 1,2 ) are non-superconductors. We found that $T_{c}$ of fullerides with composition $\mathrm{K}_{2} \mathrm{MC}_{60}$ is lower than that of $\mathrm{K}_{3} \mathrm{C}_{60}$ (excluding $\mathrm{KCsTlC}_{60}$, with $T_{c}=21.7 \mathrm{~K}$ ). Moreover, there is a correlation between lattice constant of these fullerides and their $T_{c}$, namely, lattice constant of $\mathrm{K}_{2} \mathrm{MC}_{60}$ fullerides (excluding $\mathrm{KCsTlC}_{60}$ ) is smaller than lattice constant of $\mathrm{K}_{3} \mathrm{C}_{60}$ due to smaller radii of ion substituting ion $\mathrm{K}^{+}$.

Superconductivity of triple heterofullerides $\mathrm{RbCsTlC}_{60}$ at $T_{c}=26.4 \mathrm{~K}, \mathrm{KCsTlC}_{60}$ at $T_{c}=21.7 \mathrm{~K}$, and a heterofulleride $\mathrm{Rb}_{2} \mathrm{TlC}_{60}$ at $T_{c}=27.2 \mathrm{~K}$ was discovered by investigation of temperature dependence of magnetic susceptibility. Temperature dependencies of magnetic susceptibility of these compounds are plotted in Figure 1. It should be mentioned that $\mathrm{RbCsTlC}_{60}$ and $\mathrm{Rb}_{2} \mathrm{TlC}_{60}$ transfer to superconducting state at temperatures higher than $T_{c}$ values of our previously investigated heterofullerides, synthesized by the same method. The $T_{c}=24.5 \mathrm{~K}$ of $\mathrm{Rb}_{2} \mathrm{BeC}_{60}$ was maximal, that was achieved previously $[4,6]$. The fulleride $\mathrm{KCsTlC}_{60}$ possesses the highest $T_{c}=21.7 \mathrm{~K}$ among all synthesized in the present study of heterofullerides with potassium. This confirms the suggestion that the increase of the $T_{c}$ value

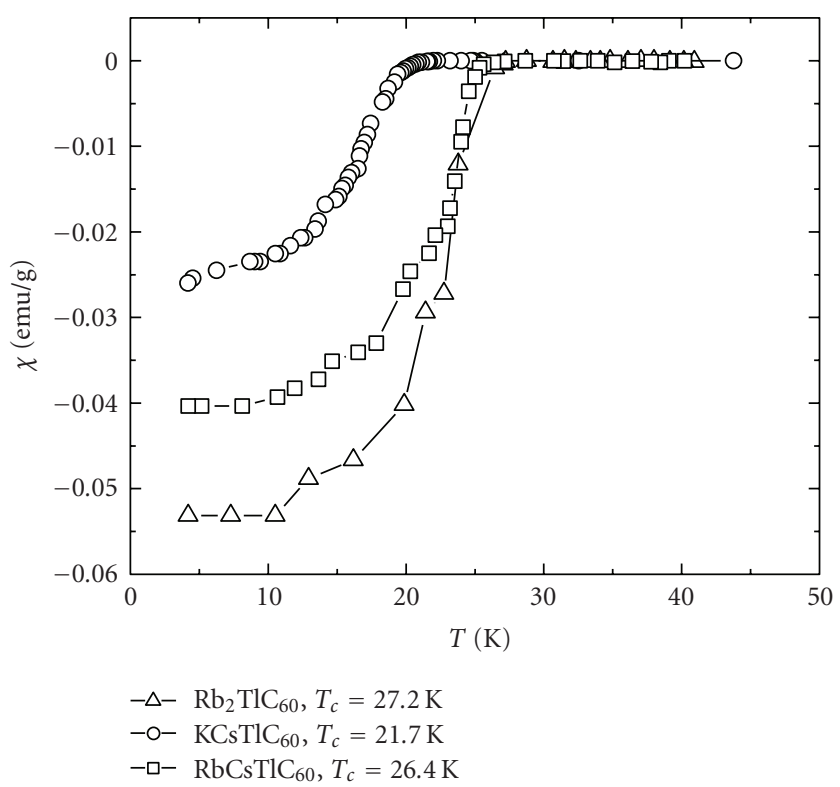

FIgURE 1: Temperature dependencies of magnetic susceptibility of $\mathrm{RbCsTlC}_{60}, \mathrm{KCsTlC}_{60}$, and $\mathrm{Rb}_{2} \mathrm{TlC}_{60}$. Superconductivity was found in new fullerides with Cs.

\begin{tabular}{|c|c|c|c|}
\hline Composition & $T_{c}(\mathrm{~K})$ & $a(\AA)$ & $r^{+}(\AA)$ \\
\hline $\mathrm{K}_{3} \mathrm{C}_{60}$ & 18.5 & $14.3110(5)$ & 1.33 \\
\hline $\mathrm{Rb}_{2} \mathrm{TlC}_{60}$ & 27.2 & $14.448(6)$ & 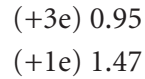 \\
\hline $\mathrm{KCsTlC}_{60}$ & 21.7 & $14.424(14)$ & 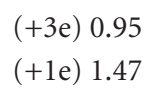 \\
\hline $\mathrm{RbCsTlC}_{60}$ & 26.4 & $14.673(17)$ & $\begin{array}{l}(+3 e) 0.95 \\
(+1 e) 1.47\end{array}$ \\
\hline
\end{tabular}

TABle 1: Composition, superconducting transition temperature $\left(T_{c}\right)$, crystal lattice parameter $(a)$, and ionic radius of heterometal $\left(r^{+}\right)$for some investigated fullerides.

is due to the increase of the lattice constant caused by substitution of $\mathrm{K}$ and $\mathrm{Rb}$ by $\mathrm{Cs}$. $\mathrm{KCsTlC}_{60}$ has maximal value of $a\left(a=1.442\right.$ nmcompared to $\left.\mathrm{K}_{3} \mathrm{C}_{60} a=1.431 \mathrm{~nm}\right)$ among all superconducting heterofullerides with potassium. The same is for $\operatorname{RbCsTlC}_{60}\left(a=1.467 \mathrm{~nm}, \mathrm{Rb}_{2} \mathrm{BeC}_{60} a=\right.$ $1.445 \mathrm{~nm})$. Such appreciable increase of the parameter $a$ of FCC lattice is quite naturally and also is one more proof of intercalation of atoms of bigger sizes in fulleride structure. There were no superconducting transitions in heterofullerides with more than one Cs atom per fullerene $\mathrm{C}_{60}$. In Table 1, parameters of two superconducting fullerides with $\mathrm{Cs}$ are shown together with $\mathrm{K}_{3} \mathrm{C}_{60}$ and $\mathrm{Rb}_{2} \mathrm{TlC}_{60}$ for comparison.

\subsection{X-ray Data}

According to RFA, data majority of heterofullerides with Cs are amorphous. All attempts to synthesize caesium heterofullerides by interaction of homofullerides $\mathrm{Cs}_{n} \mathrm{C}_{60}$ 


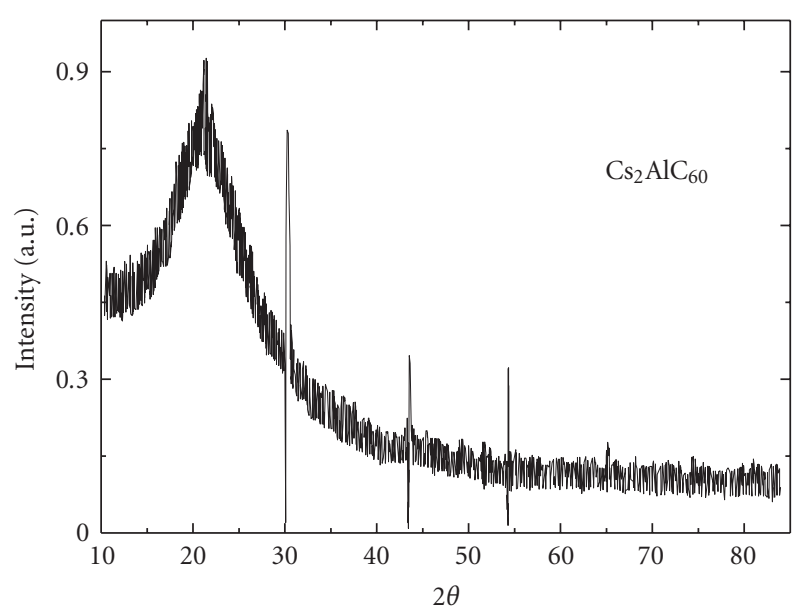

(a)

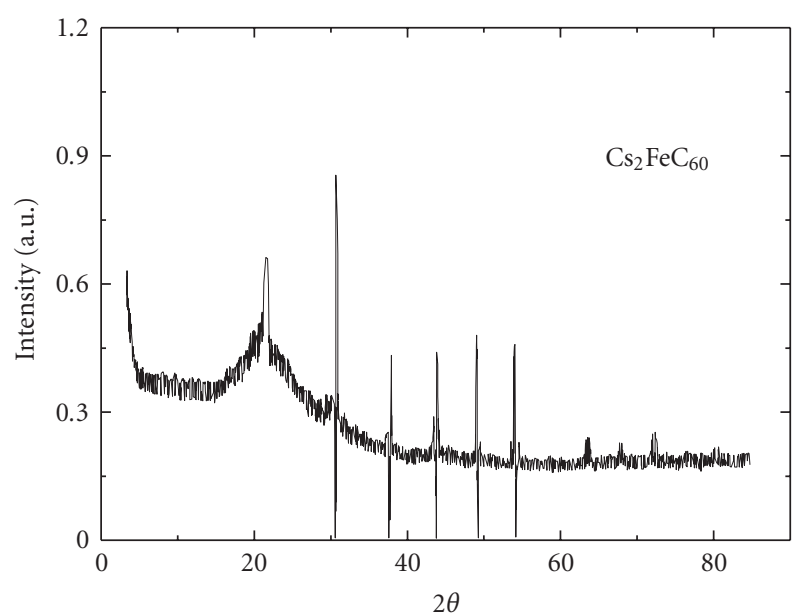

(b)

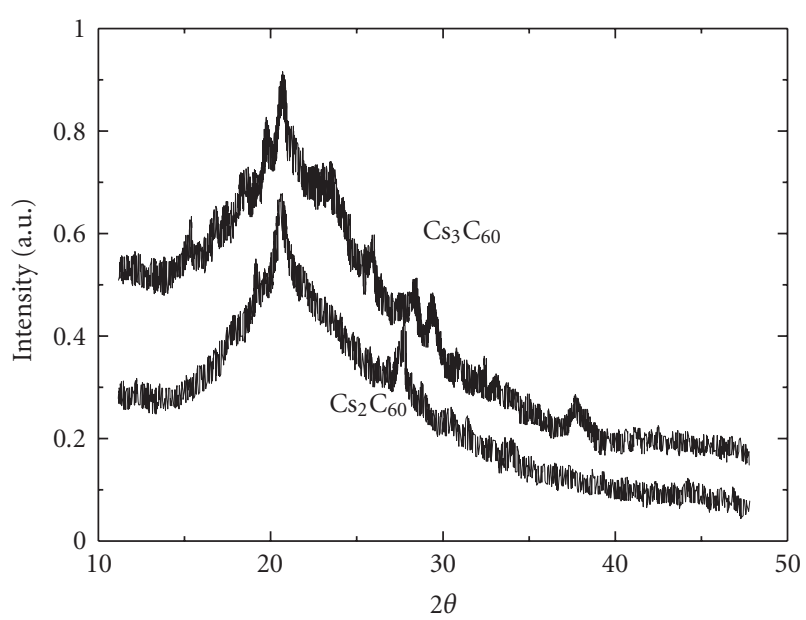

(c)

Figure 2: Diffractogram of $\mathrm{Cs}_{2} \mathrm{AlC}_{60}, \mathrm{Cs}_{2} \mathrm{FeC}_{60}$, and $\mathrm{Cs}_{2} \mathrm{C}_{60}$, $\mathrm{Cs}_{3} \mathrm{C}_{60}$. Vertical lines show peaks of $\mathrm{CsCl}$. There is no reflection from fulleride crystal lattice.

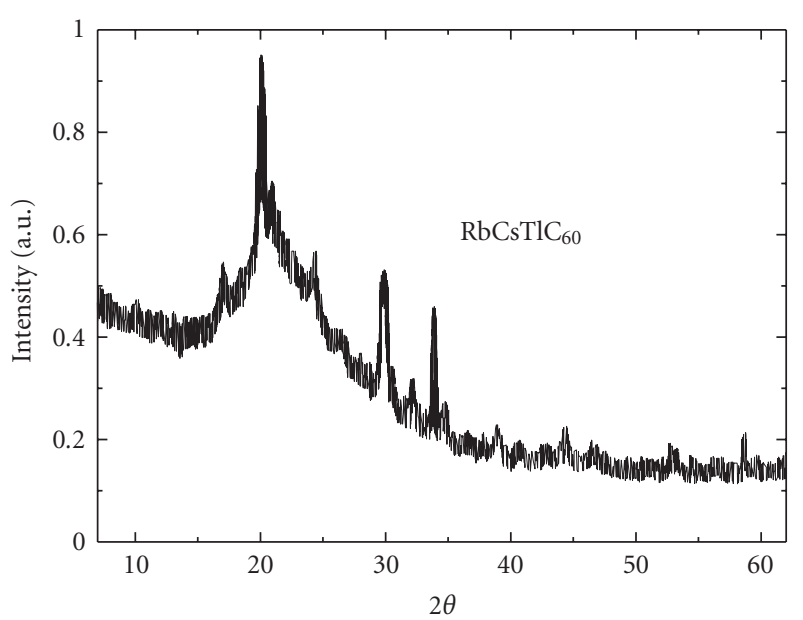

Figure 3: Diffractogram of fulleride $\mathrm{RbCsTlC}_{60}$ synthesized by (4) mixed with the product of reaction $\mathrm{CsCl}$.

with chlorides of beryllium, magnesium, calcium, barium, aluminum, and iron on (1) and (3) lead to nonsuperconducting X-ray amorphous samples (Figure 2). One can see only wide peak (halo) at $2 \theta \approx 20.2^{\circ}$ and peaks identified as crystalline $\mathrm{CsCl}$ in $\mathrm{X}$-ray spectrum. As in $\mathrm{C}^{13}$ NMR spectra of these samples, there is no resonance at 170-200 ppm, which is common for all homo- and heterofullerides with FCC lattice with freely rotating anion $\mathrm{C}_{60}{ }^{-n}$. We assume that caesium fullerides are not simply amorphous, but polymeric substances.

The results of interaction of $\mathrm{Cs}_{3} \mathrm{C}_{60}$ with $\mathrm{TlCl}$, according to (4), do not give any new information. But in reaction of thallium chloride with alkali metal heterofullerides, according to (4), obtained heterofullerides are crystalline substances (Figure 3 ) and superconductors.

\subsection{Raman Scattering}

The results of measurement and investigation of Raman scattering of fullerides $\mathrm{Cs}_{2} \mathrm{C}_{60}, \mathrm{Cs}_{3} \mathrm{C}_{60}, \mathrm{Cs}_{2} \mathrm{MC}_{60}(\mathrm{M}=\mathrm{Ca}, \mathrm{Ba})$ showed that these fullerides are most likely not crystalline. This is testified by the absence of nearly all characteristic fullerene $\mathrm{C}_{60}$ phonon modes (Figure 4). The lines in Raman spectra are strongly shifted and extended compared to the lines of pure fullerite. Thus one cannot definitely identify presented lines and estimate the charge state of $\mathrm{C}_{60}$ molecule in these compounds.

The absence of the majority of oscillatory modes observed in $\mathrm{K}_{3} \mathrm{C}_{60}$ spectrum specifies polymerization (more rigid fixing of molecules $\mathrm{C}_{60}$ ).

On the basis of X-ray and Raman spectra, one can conclude that fullerides and heterofullerides of caesium are polymers. This fact can explain the absence of superconductivity in these compounds because polymerization suppresses the phonon modes of $\mathrm{C}_{60}$ molecules that mediate electronelectron attraction [7]. Besides, polymerization may cause transition to the dielectric state. 


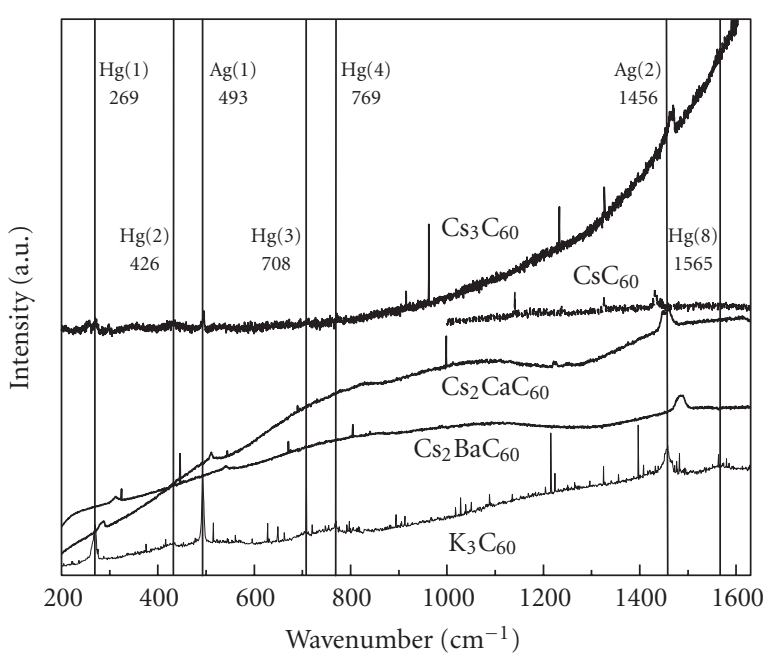

(a)

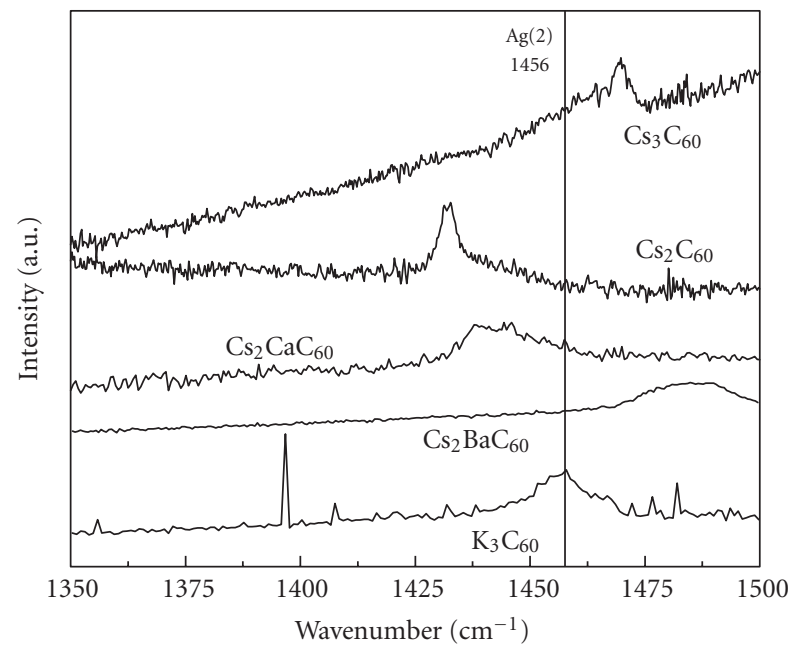

(b)

Figure 4: Raman scattering spectra of fullerides $\mathrm{Cs}_{2} \mathrm{C}_{60}, \mathrm{Cs}_{3} \mathrm{C}_{60}$, and $\mathrm{Cs}_{2} \mathrm{MC}_{60}(\mathrm{M}=\mathrm{Ca}, \mathrm{Ba})$ obtained at (a) room temperature and (b) Raman spectra in the range near line $\operatorname{Ag}(2)$ of $\mathrm{K}_{3} \mathrm{C}_{60}$ for the same fullerides.

\subsection{Electron Paramagnetic Resonance}

In EPR spectrum of $\mathrm{CsMg}_{2} \mathrm{C}_{60}$, there are two lines, the second one has higher g-factor and is much wider than the main line. Parameters of this line are shown in Table 2. Intensity of this line decreases as temperature decreases and it is not visible for $T<120 \mathrm{~K}$. The most probably explanation of the drastically decrease of the intensity is due to transition of paramagnetic centers to the different spin states. The nature of these centers at the moment is unknown.

The analysis of electron paramagnetic resonance (EPR) spectra and their temperature dependence revealed the presence of at least two different types of paramagnetic centers, that is, two lines of different widths, in superconducting fullerides $\mathrm{A}_{2} \mathrm{MC}_{60}(\mathrm{~A}=\mathrm{K}, \mathrm{Rb}, \mathrm{M}=\mathrm{Be}, \mathrm{Mg})$-Figure 5 .

Temperature dependence of paramagnetic susceptibility (double-integrated EPR signal) of narrow line is described

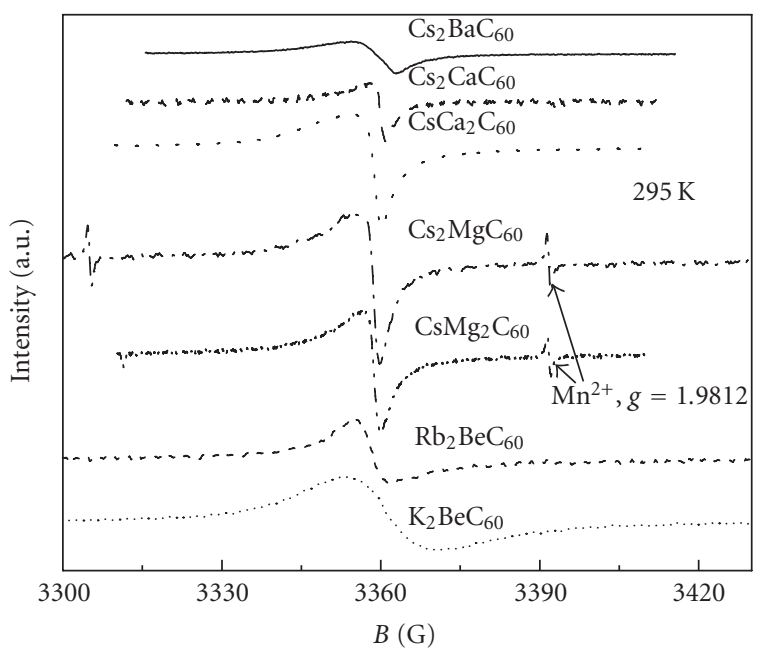

FIGURE 5: Asymmetric of EPR spectra heterofullerides with Cs pointed out to asymmetric environment of molecule $\mathrm{C}_{60}$ due to possible polymerization.

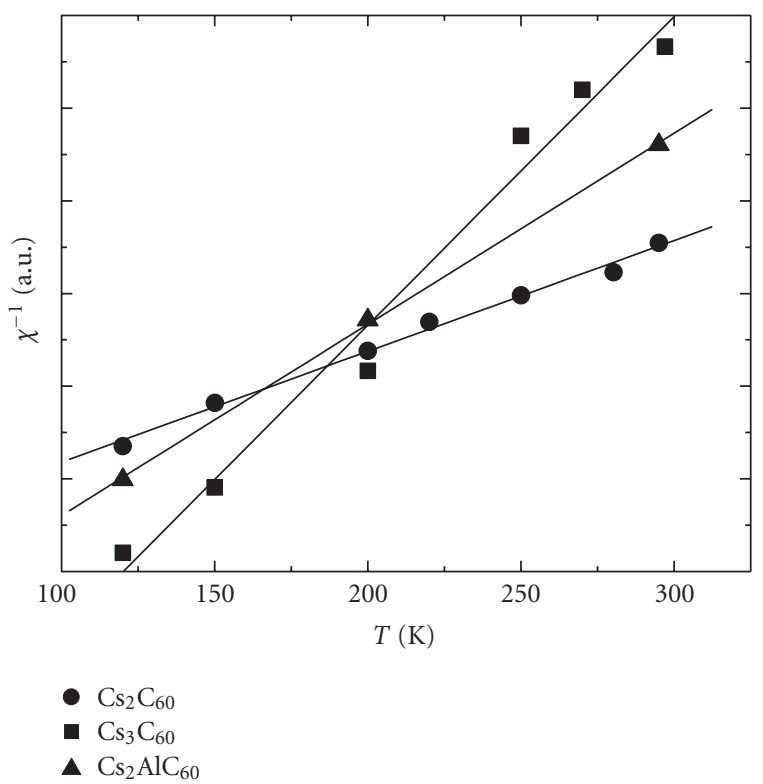

FIGURE 6: Temperature dependence of paramagnetic susceptibility $\chi$ (double-integrated EPR signal) non-superconducting fullerides with Cs. Curie-Weiss law (fitting by solid lines) is a consequence of the absence of conduction electrons (no contribution to the paramagnetic susceptibility).

by Curie-Weiss law Figure 6 . Therefore, the appropriate paramagnetic centers obey Bolzman statistics and probably are due to electron-charged defects like $\mathrm{C}_{60}-\mathrm{O}$ or $\mathrm{C}_{60}-\mathrm{O}-\mathrm{C}_{60}$ $[8,9]$. Temperature dependence of parameters of broad line (second type of centers) is weak. This points out to the Fermi statistics of the centers of the second type, presumably they are conduction electrons $[10,11]$.

At the same time, EPR spectra of non-superconducting fullerides with the composition $\mathrm{Cs}_{x} \mathrm{C}_{60}(x=2,3), \mathrm{Cs}_{2} \mathrm{AlC}_{60}$ can be described by anisotropic signal of only one type of 


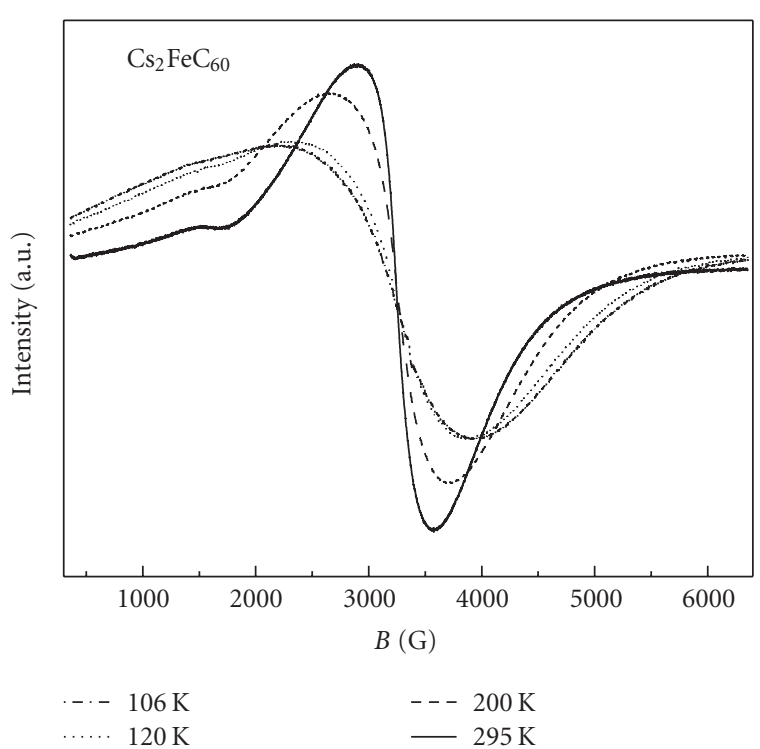

Figure 7: EPR spectra at different temperatures of $\mathrm{Cs}_{2} \mathrm{FeC}_{60}$.

TABle 2: Average line width $\Delta \mathrm{Hpp}$ and $g$-factor of EPR for nonsuperconducting fullerides of $\mathrm{Cs}$ and $\mathrm{Mg}$.

\begin{tabular}{lcccc}
\hline Composition & $\begin{array}{l}\Delta \mathrm{Hpp} \text { and } \\
g \text {-factor }\end{array}$ & 297 & $\begin{array}{c}\mathrm{T}(\mathrm{K}) \\
200\end{array}$ & 120 \\
\hline $\mathrm{Cs}_{2} \mathrm{MgC}_{60}$ & $g$ & & $2.0010 \pm 0.0003$ & \\
& $\Delta \mathrm{Hpp}(\mathrm{Oe})$ & 4.8 & 5.4 & 7.3 \\
\hline $\mathrm{CsMg}_{2} \mathrm{C}_{60}$ & $g$ & & $2.0010 \pm 0.0003$ & \\
& $\Delta \mathrm{Hpp}(\mathrm{Oe})$ & 3.3 & 4.4 & 7.2 \\
\hline $\mathrm{CsMg}_{2} \mathrm{C}_{60}$ & $g$ & 2.2335 & 2.2785 & - \\
$($ wide line $)$ & $\Delta \mathrm{Hpp}(\mathrm{Oe})$ & 248 & 221 & - \\
\hline $\mathrm{K}_{2} \mathrm{MgC}_{60}$ & $g$ & & $2.0010 \pm 0.0003$ & \\
& $\Delta \mathrm{Hpp}(\mathrm{Oe})$ & 3.7 & 2.7 & 2.1 \\
\hline $\mathrm{KMg}_{2} \mathrm{C}_{60}$ & $g$ & & $2.0009 \pm 0.0003$ & \\
& $\Delta \mathrm{Hpp}(\mathrm{Oe})$ & 5 & 2.4 & 1.8 \\
\hline
\end{tabular}

paramagnetic signals with Bolzman statistics, that is, defects with odd electron charge. This follows from temperature dependence of lineshape and paramagnetic susceptibility, calculated by double integration of EPR spectra. In the investigated temperature range ( $105 \mathrm{~K}-300 \mathrm{~K})$, paramagnetic susceptibility can be well fitted by Curie-Weiss law. The extraction of the signal from conducting electrons with temperature-independent paramagnetic susceptibility for ERP spectra of these fullerides is not possible, indicating that the density of electrons is low. This fact is confirmed by the absence of superconducting transition in this fullerides.

In Figure 7, we plotted ERR spectra for $\mathrm{Cs}_{2} \mathrm{FeC}_{60}$ fulleride. The width of the line increases while the amplitude decreases when temperature decreases, notification of ferromagnetic resonance. Some parameters of EPR signals for non-superconducting fullerides are listed in Table 2.

\section{Conclusions}

Exchange reactions of caesium fullerides with anhydrous metal chlorides lead to polymeric and non-superconducting phases. The exception is ternary fullerides with supposed composition of RbCsTlC 60 with $T_{c}=26.4 \mathrm{~K}$ and $\mathrm{KCsTlC}_{60}$ with $T_{c}=21.7 \mathrm{~K}$. As it is known for alkali metal fullerides, $T_{c}$ depends linear on the lattice parameter $a$ and the same linear law was found for synthesized superconducting heterofullerides.

The EPR spectra of non-superconducting fullerides with the composition $\mathrm{Cs}_{n} \mathrm{C}_{60}(n=2,3), \mathrm{Cs}_{2} \mathrm{AlC}_{60}$ can be described by anisotropic signal, that originate from one type of paramagnetic centers with Bolzman statistics. Most likely, these centers are odd-charged defects $\mathrm{C}_{60}-\mathrm{O}$ or $\mathrm{C}_{60}-$ $\mathrm{O}-\mathrm{C}_{60}$. The results of measurement and investigation of Raman scattering of fullerides $\mathrm{Cs}_{2} \mathrm{C}_{60}, \mathrm{Cs}_{3} \mathrm{C}_{60}, \mathrm{Cs}_{2} \mathrm{MC}_{60}$ $(\mathrm{M}=\mathrm{Ca}, \mathrm{Ba})$ showed that these fullerides are polymers. This fact simultaneously with absence of conduction electrons can explain the non-superconducting character of these compounds because polymerization suppresses the phonon modes of $\mathrm{C}_{60}$ molecules that mediate electron-electron attraction.

\section{Acknowledgment}

The work was supported by RFBR, Grant no. 08-03-00237-a. The measurements of EPR and Raman spectra were carried out on the equipment of the Center of Users' Facilities of Moscow State University.

\section{References}

[1] O. Gunnarsson, "Superconductivity in fullerides," Reviews of Modern Physics, vol. 69, no. 2, pp. 575-606, 1997.

[2] V. G. Kytin, B. M. Bulychev, A. V. Krechetov, et al., "Study of the paramagnetic centers in heterofullerides $\mathrm{M}_{n} \mathrm{M}_{3-n}^{\prime} \mathrm{C}_{60}$ ( $\mathrm{M}$ = K, Rb, Cs; $\left.\mathrm{M}^{\prime}=\mathrm{Be}, \mathrm{Mg}, \mathrm{Ca}, \mathrm{Ba} ; n=1,2\right)$," Russian Journal of Inorganic Chemistry, vol. 53, no. 1, pp. 36-41, 2008 (Russian).

[3] B. M. Bulychev, R. A. Lunin, V. A. Kul'bachinskii, R. V. Shpanchenko, and V. I. Privalov, "Fullerides: heterometallic superconductors with composition $\mathrm{M}_{2} \mathrm{M}^{\prime} \mathrm{C}_{60}\left(\mathrm{M}=\mathrm{K}, \mathrm{Rb} ; M^{\prime}\right.$ = Yb, Lu, Sc)," Russian Chemical Bulletin, vol. 53, no. 8, pp. 1686-1692, 2004.

[4] B. M. Bulychev, R. A. Lunin, A. V. Krechetov, et al., "Heterometallic fullerides of $\mathrm{Fe}$ and $\mathrm{Cu}$ groups with the composition $\mathrm{K}_{2} \mathrm{MC}_{60}\left(\mathrm{M}=\mathrm{Fe}^{+2}, \mathrm{Fe}^{+3}, \mathrm{Co}^{+2}, \mathrm{Ni}^{+2}, \mathrm{Cu}^{+1}, \mathrm{Cu}^{+2}\right.$, $\mathrm{Ag}^{+1}$ )," Journal of Physics and Chemistry of Solids, vol. 65, no. 2-3, pp. 337-342, 2004.

[5] O. A. Dityatyev, V. I. Privalov, B. M. Bulychev, A. A. Dityat'ev, and V. N. Bezmelnitsyn, "Synthesis of sodium and potassium fullerides in aromatic hydrocarbons," Molecular Crystals and Liquid Crystals Science and Technology A, vol. 13, no. 1-4, pp. 281-284, 2000.

[6] A. V. Krechetov, V. G. Kytin, E. A. Konstantinova, V. A. Kulbachinskii, R. A. Lunin, and B. M. Bulychev, "Investigation of fullerides $\mathrm{A}_{2} \mathrm{MC}_{60}$ and $\mathrm{AM}_{2} \mathrm{C}_{60}(\mathrm{~A}=\mathrm{K}, \mathrm{Rb}, \mathrm{M}=\mathrm{Mg}, \mathrm{Be})$ by electron spin resonance method," in Proceedings of the 3 rd International Conference on Flow Dynamics (ICFD '06), p. 193, Matsushima, Japan, November 2006. 
[7] V. Buntar and H. W. Weber, "Magnetic properties of fullerene superconductors," Superconductor Science and Technology, vol. 9, no. 8, pp. 599-615, 1996.

[8] C. A. Reed and R. D. Bolskar, "Discrete fulleride anions and fullerenium cations," Chemical Reviews, vol. 100, no. 3, pp. 1075-1120, 2000.

[9] A. V. Egorov, A. V. Krechetov, P. S. Samokhvalov, et al., "Modified phases of fullerite $\mathrm{C}_{60}$ : synthesis and properties," in Proceedings of the International Conference on Carbon Nanostructures, pp. 285-291, Minsk, Belarus, 2006.

[10] J. Robert, P. Petit, T. Yildirim, and J. E. Fischer, "Experimental lattice dependence of the density of states in alkali fullerides," Physical Review B, vol. 57, no. 2, pp. 1226-1230, 1998.

[11] A. Jánossy, O. Chauvet, S. Pekker, J. R. Cooper, and L. Forró, "Conduction electron spin resonance in $\mathrm{Rb}_{3} \mathrm{C}_{60}$," Physical Review Letters, vol. 71, no. 7, pp. 1091-1094, 1993. 

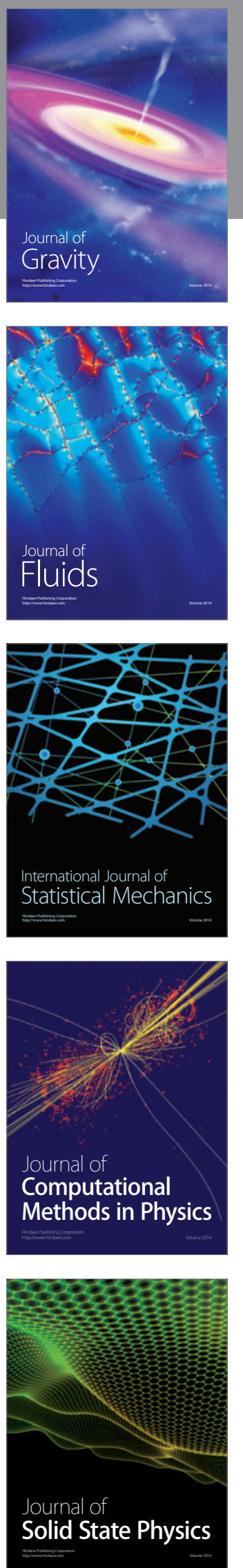

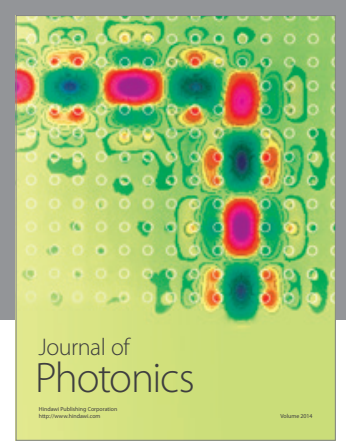

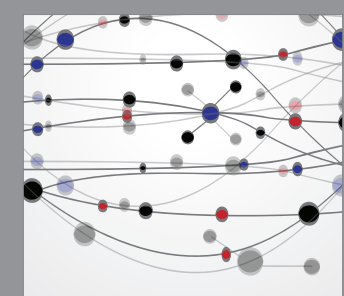

The Scientific World Journal
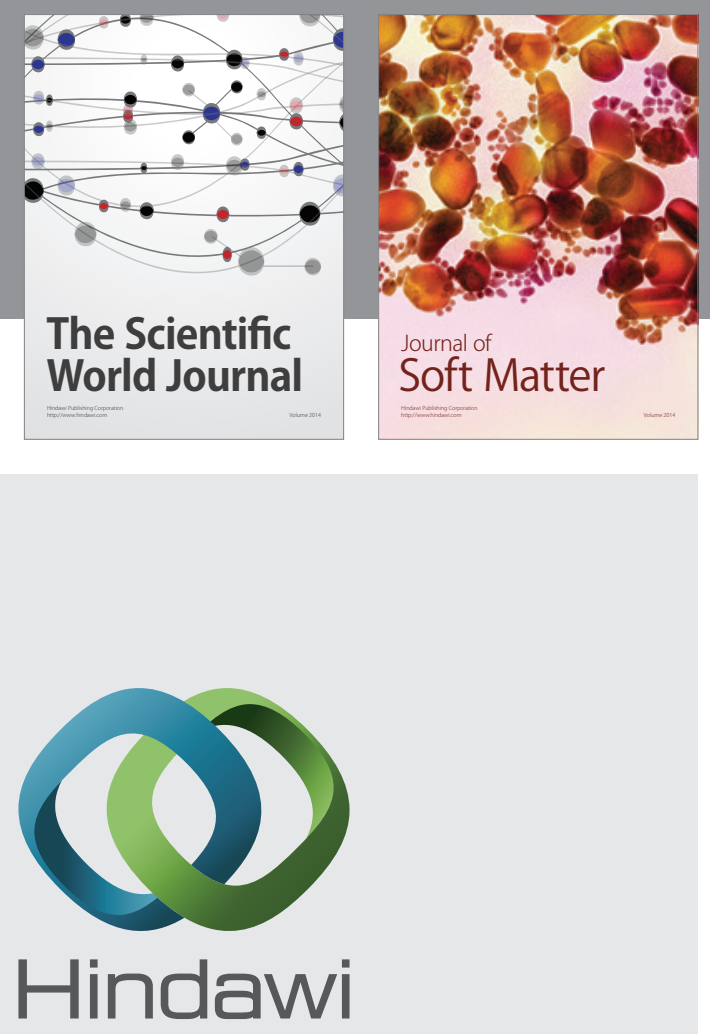

Submit your manuscripts at

http://www.hindawi.com
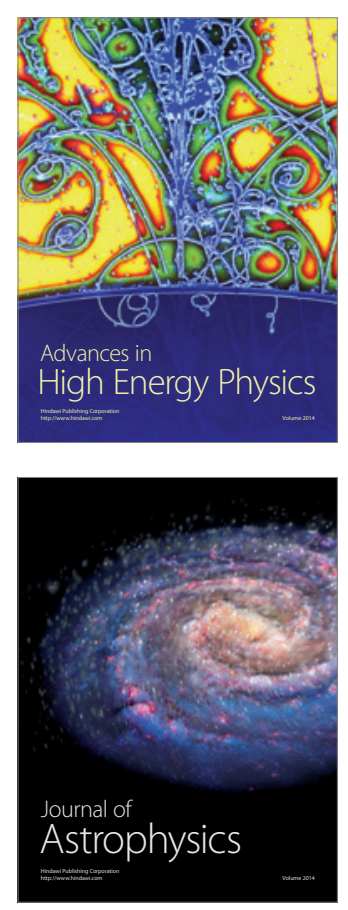
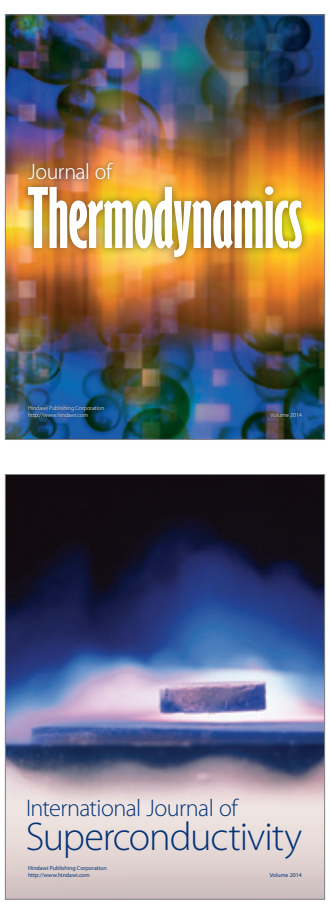
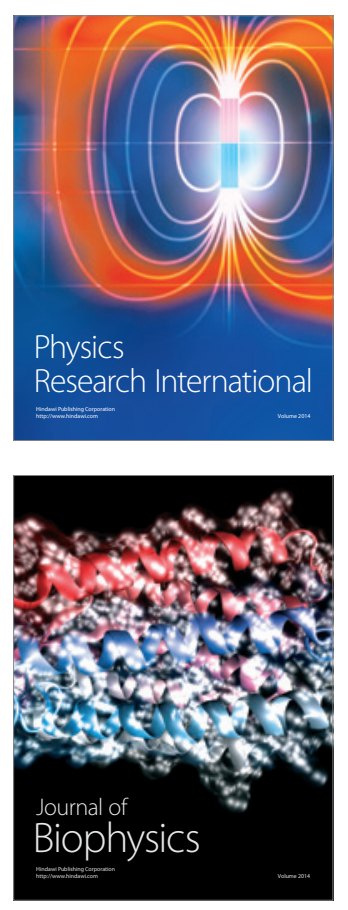
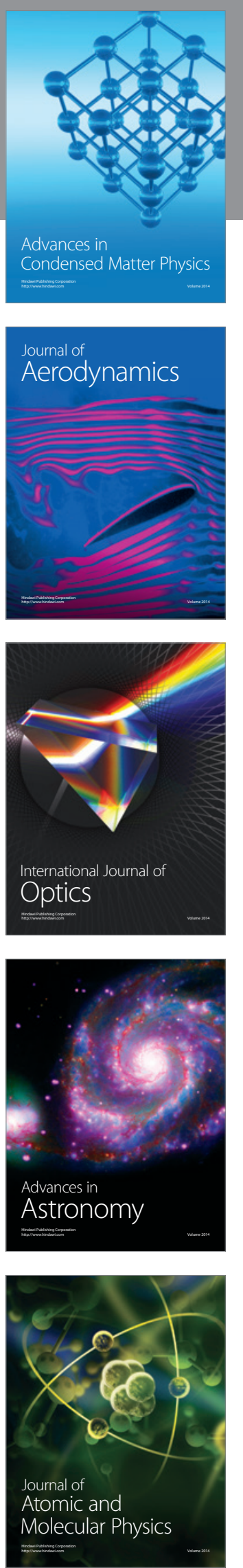